$15^{\text {th }}$ International Conference on

AEROSPACE SCIENCES \& AVIATION TECHNOLOGY,

ASAT - 15 - May 28 - 30, 2013, Email: asat@mtc.edu.eg,

Military Technical College, Kobry Elkobbah, Cairo, Egypt,

Tel: +(202) 24025292 -24036138, Fax: +(202) 22621908

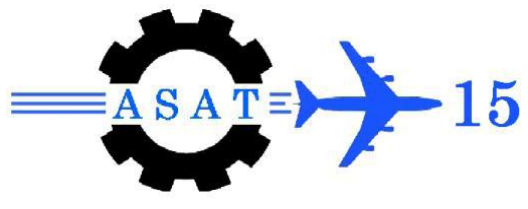

\title{
Elastic Buckling of Rectangular Hollow Section Tapered Columns Subjected to Uniform Compressive Stresses
}

\author{
A. H. Salem* , N. H. Abdelmtaal ${ }^{\dagger}$, M. M. Abdel Wahab ${ }^{\dagger}$, and Zoulfikar Al-Yassin
}

\begin{abstract}
This paper presents a theoretical analysis for rectangular hollow section (RHS) tapered columns in order to define the elastic critical buckling loads of the columns subjected to uniform compressive stresses. The critical buckling load of (RHS) tapered column is affected by the buckling coefficient of plate elements which is a function of the type of loading, edge support conditions, the plate aspect ratio, and the tapering ratio. A simple and convenient method is proposed using the energy method in order to formulate the necessary equations, which takes into consideration the web-flange interaction and effect of tapering ratio of web on the buckling coefficient of the section. The results are represented diagrammatically as function of the ratio of buckling load to average area yield load with respect to the different mentioned ratios. A comparison between the buckling coefficient as obtained by the energy method and the finite element method through ANSYS program is also performed.
\end{abstract}

Keywords: Buckling coefficient, tapering ratio, aspect ratio, plates, hollow section columns.

\section{Nomenclature}

L plate length (length of column), (mm)

b Plate width (mm)

$\mathrm{d}_{\mathrm{w} 2} \quad$ Wide web width, $(\mathrm{mm})$

$\mathrm{d}_{\mathrm{w} 1} \quad$ narrow web width, $(\mathrm{mm})$

dw $w_{a v}$ average web width, $(\mathrm{mm})$

$\mathrm{T}$ plate thickness, $(\mathrm{mm})$

$\mathrm{d}_{\mathrm{f}} \quad$ flange depth, (mm)

E Young's modulus of elasticity, $\left(\mathrm{N} / \mathrm{mm}^{2}\right)$

$V \quad$ Poisson's ratio

$\mathrm{A}_{\mathrm{gr}} \quad$ gross sectional area

$\mathrm{P}_{\mathrm{cr}} \quad$ Critical load

$\mathrm{P}_{\mathrm{y} \cdot \mathrm{av}} \quad$ yield capacity $=\sigma_{\mathrm{y}} \cdot \mathrm{A}_{\mathrm{av}}$.

$\mathrm{K}$ buckling coefficient of the rectangular plate

$\mathrm{K}_{\mathrm{tr}} \quad$ buckling coefficient of the trapezoidal plate

$\mathrm{K}_{\mathrm{H}} \quad$ buckling coefficient of hollow section member

$\sigma_{\text {cr }} \quad$ elastic critical stress, $\left(\mathrm{N} / \mathrm{mm}^{2}\right)$

$\mathrm{R} \quad$ tapering ratio $=\left(\mathrm{d}_{\mathrm{w} 2} / \mathrm{d}_{\mathrm{w} 11}\right)$

\footnotetext{
Structural Engineering Department, Ain Shams University, Cairo, Egypt.

$\dagger \quad$ Egyptian Armed Forces, Egypt.

¥ Syrian Arabic Armed Forces, Syria; abeerzouf@yahoo.com
} 


\section{Introduction}

Steel members with non-prismatic cross-section have quite a good number of applications in modern structures. Non- prismatic (trapezoidal) plate structures can be found frequently in modern construction in the form of reinforced and stiffened plates. Such structures are widely used as floors in bridges, ship hulls, hangars and industrial buildings, etc. Trapezoidal plates are also used in the construction of wings, tails and fins of aircrafts. Depending on the mode of application, a plate element can be subjected to various in-plane forces (compression, bending, shear or a combination of these stresses). Compression members can fail by yielding, inelastic buckling, or elastic buckling depending on the slenderness ratio of the members. Members with low slenderness ratios tend to fail by yielding while members with high slenderness ratios tend to fail by elastic buckling. The buckling of plates plays an important role in structural safety and has been an important area of research. The stability of hollow section columns, under the action of compressive forces uniformly distributed along the edges, was discussed by several authors as presented in the following:

Yang, Hancock and Rasmussen [1] presented a series of compression tests performed on pinended long columns with box-sections fabricated from cold-formed high strength steel plates with nominal yield stress of $550 \mathrm{MPa}$.

Salem et al. [2] presented a numerical analysis to investigate the ultimate loads and the failure modes of axially loaded steel columns composed of cold-formed rectangular hollow sections (RHS).

Yang and Hancock [3, 4 and 5] presented a series of compression tests on cold-formed steel columns fabricated from cold-formed high strength steel plates with nominal yield stress of $550 \mathrm{MPa}$. The specimens included stub columns and long columns. Three different cross section stub columns, namely box, lipped-box and hexagonal shaped specimens were tested between fixed ends.

Derrick and Hancock [6] presented the experimental investigation of series of compressive tests on stiffened-cross shaped section columns fabricated from cold-formed high strength steel of thickness $0.42 \mathrm{~mm}$ and nominal yield stress of $550 \mathrm{MPa}$. The varying lengths were chosen so as to observe the buckling modes and the possibility of interaction between them. There are many other sources of information on elastic local buckling of plates [7, 8, 9].

The elastic critical load of rectangular simply supported plate under compression Fig. 1a can be expressed as:

in which:

$$
\mathrm{P}_{\mathrm{cr}}=\mathrm{A}_{\mathrm{gr}} \cdot \sigma_{\mathrm{cr}}
$$

$\mathrm{A}_{\mathrm{gr}}$ - is the gross sectional area $=$ b.t,

$\sigma_{\mathrm{cr}^{-}}$is the elastic critical stress. determined as follows:

$$
\sigma_{\mathrm{cr}}=\mathrm{K} \frac{\pi^{2} \mathrm{E}}{12\left(1-\mathrm{v}^{2}\right)}\left(\frac{\mathrm{t}}{\mathrm{b}}\right)^{2}
$$

where $\mathrm{K}$ is a dimensionless buckling coefficient of the plate and depends on the type of loading, edge support conditions, and the plate aspect ratio $\Phi=\mathrm{L} / \mathrm{b}$, while $\mathrm{E}$ and $v$ are the Young's modulus and Poisson's ratio of the plate material, respectively. It was found that for the case of a rectangular plate, simply supported along its four edges and subjected to uniform compression at the two opposite short edges, the value of $\mathrm{K}$ can be written as: 


$$
\mathrm{K}=\left(\frac{\mathrm{mb}}{\mathrm{L}}+\frac{\mathrm{L}}{\mathrm{mb}}\right)^{2}, \quad \mathrm{~m}=1,2,3, \ldots \ldots
$$

where, $m$ corresponds to the number of half waves that occur in the plate's longitudinal direction at buckling, i.e. $m$ defines the buckling mode of the plate. The above equation was illustrated graphically in many textbooks and gives a minimum value of 4.0 for the buckling coefficient $\mathrm{K}$. This minimum value occurs when $(\mathrm{L} / \mathrm{b})$ is an integer. For trapezoidal plates, $\mathrm{K}$ also depends on the type of loading, edge support conditions, and the plate aspect ratio $\Phi=\mathrm{L} / \mathrm{b}$, which is a function of the tapering ratio $\mathrm{R},\left(\mathrm{R}=\mathrm{d}_{\mathrm{w} 2} / \mathrm{d}_{\mathrm{w} 1}\right.$, see Fig. $\left.1 \mathrm{~b}\right)$.

Substituting Eq.(2) in Eq.(1), leads to

$$
P_{c r}=K \frac{\pi^{2} E}{12\left(1-v^{2}\right)}\left(\frac{t}{b}\right)^{2} \cdot A_{g r}
$$

\section{Theoretical Analysis}

Consider the rectangular hollow section shown in Fig. 1a. The energy method, in which the total strain energy of distortion of the plates is equated to the work done by the axial stress in the longitudinal direction as buckling occurs, is used to obtain the local initial elastic critical stress. The strain energy due to bending of the plate of width $b$, simply supported along the four edges, can be written in terms of deflections as follow:

$$
\mathrm{U}=\frac{1}{2} \cdot \mathrm{D} \iint\left[\left(\frac{\partial^{2} \mathrm{w}}{\partial \mathrm{x}^{2}}+\frac{\partial^{\mathrm{z}} \mathrm{w}}{\partial \mathrm{y}^{2}}\right)^{2}-2 \cdot(1-\mathrm{v}) \cdot\left(\frac{\partial^{\mathrm{z}} \mathrm{w}}{\partial \mathrm{x}^{2}} \cdot \frac{\partial^{\mathrm{z}} \mathrm{w}}{\partial \mathrm{y}^{2}}-\left(\frac{\partial^{\mathrm{x}} \mathrm{w}}{\partial \mathrm{x} \partial \mathrm{y}}\right)^{2}\right)\right] \mathrm{dxdy}
$$

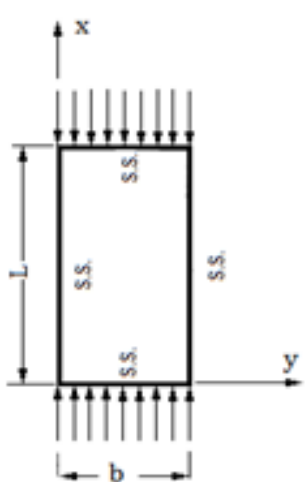

(a)- Rectangular plate under compressive Load
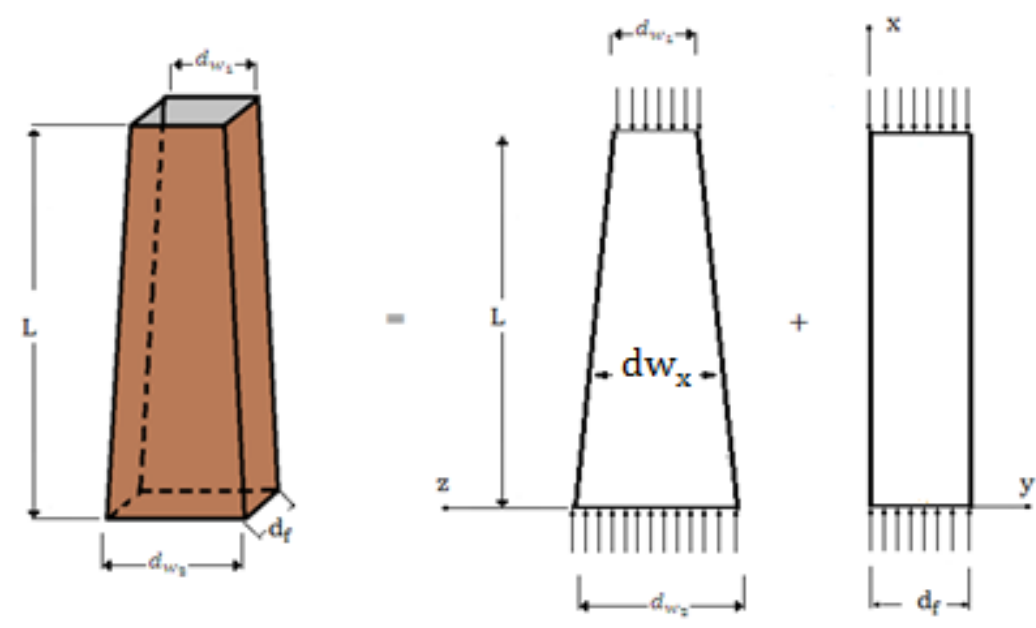

(b)- Hollow thin section tapered column

Fig. 1 Plate under compressive stresses

Furthermore the equation describing the work conducted by the externally applied forces is:

$$
\mathrm{T}=\frac{1}{2} \iint\left[\mathrm{N}_{\mathrm{x}} \frac{\partial^{\mathrm{z}} \mathrm{w}}{\partial \mathrm{x}^{\mathrm{z}}}\right] \mathrm{dxdy}
$$

A simple energy analysis may be obtained by assuming the plate buckling deflection surfaces of the wide and narrow faces are both sinusoidal: 


$$
\mathrm{w}=\sum_{\mathrm{m}=1,2,3_{a \mathrm{~m}}} \sum_{\mathrm{n}=1,2,3_{3, \mathrm{~m}}} \mathrm{w}_{\mathrm{mn}} \sin \frac{\mathrm{mmx}}{\mathrm{L}} \sin \frac{\mathrm{nmy}}{\mathrm{b}}
$$

To simplify the mathematical calculation, it was found that using one term of the double Fourier series may give accurate results. So " $\mathrm{w}_{\mathrm{f}}{ }^{\mathrm{T}}$ the plate buckling deflection of narrow (flange) face $d_{f}$ can be considered as:

$$
w_{\mathrm{f}}=A_{\mathrm{f}} \sin \frac{\mathrm{m} \pi \mathrm{x}}{\mathrm{L}} \sin \frac{\mathrm{nmy}}{\mathrm{d}_{\mathrm{f}}}
$$

Equation (8) satisfies the hinged boundary conditions for the plate, that is:

$$
w_{f}=0, \frac{\partial^{2} w}{\partial x^{2}}=0, \frac{\partial^{2} w}{\partial y^{2}}=0 \text {, at any of }\left\{\begin{array}{l}
x=0 \\
x=L \\
y=0 \\
y=d_{f}
\end{array}\right.
$$

and " $w_{\mathrm{w}}{ }^{\mathrm{w}}$ the plate buckling deflection of wide (web) face $\mathrm{d}_{\mathrm{w}}$ can be obtained as:

$$
\mathrm{w}_{\mathrm{w}}=\mathrm{A}_{\mathrm{w}} \sin \frac{\mathrm{m \pi x}}{\mathrm{L}} \sin \frac{\mathrm{n \pi z}}{\mathrm{d}_{\mathrm{w}}}
$$

Equation (10) satisfies the hinged boundary conditions for the plate, that is:

$$
w_{w}=0, \frac{\partial^{2} w}{\partial x^{2}}=0, \frac{\partial^{2} w}{\partial z^{2}}=0, \text { at any of }\left\{\begin{array}{l}
x=0 \\
x=L \\
z=0 \\
z=d_{w}
\end{array}\right.
$$

The $\mathrm{x}$ and $\mathrm{y}$ coordinates are nondimensionalized according to the following relationships:

$$
\begin{aligned}
& X=\xi . L \quad: 0 \leq \xi \leq 1 \\
& \mathrm{Y}=\eta \cdot \mathrm{d} w_{\mathrm{x}} \quad: 0 \leq \eta \leq 1 \\
& d w_{x}=d w_{2}-\left(\frac{d w_{2}-d w_{1}}{L}\right) \cdot x \\
& =d w_{2}-\left(d w_{2}-d w_{1}\right) \cdot \xi \\
& \mathrm{dw}=\int_{0}^{1} \mathrm{dw}_{\mathrm{x}^{*}} \mathrm{~d} \xi=\frac{\mathrm{dw}_{\mathrm{z}}+\mathrm{dw}_{1}}{2}=\mathrm{dw}_{\mathrm{av}} \\
& d w_{a v}=\frac{d w_{2}(R+1)}{2 R} \text {, Let } R=\frac{\mathrm{dw}_{2}}{\mathrm{dw}_{1}} \geq 1.0 \text { and } \varphi=\frac{\mathrm{dw}_{\mathrm{z}}}{\mathrm{df}}
\end{aligned}
$$

Substitution of Eq. (8), then Eq. (10) in Eq. (5) and (6). Note that integrate of the $2^{\text {nd }}$ term of Eq.(4) over the plate it equals zero;

$$
-2 \cdot(1-\mathrm{v}) \cdot \int_{0}^{\mathrm{a}} \int_{0}^{\mathrm{b}}\left[\frac{\partial^{\mathrm{z}} \mathrm{w}}{\partial \mathrm{x}^{2}} \cdot \frac{\partial^{\mathrm{z}} \mathrm{w}}{\partial \mathrm{y}^{2}}-\left(\frac{\partial^{\mathrm{z}} \mathrm{w}}{\partial \mathrm{x} \partial \mathrm{y}}\right)^{2}\right] \mathrm{dxdy}=0
$$

For the flange the strain energy is given by:

$$
\mathrm{U}_{\mathrm{f}}=\frac{1}{2} \cdot D \pi^{4}\left[\left(\frac{m^{2}}{L^{2}}+\frac{n^{2}}{b^{2}}\right)^{2}\right] \int_{0}^{a} \int_{0}^{b} w^{2} d x d y
$$

Differentiating Eq. (14), $\mathrm{U}_{\mathrm{f}}$ can be found as:

$$
\mathrm{U}_{\mathrm{f}}=\frac{\pi^{4} \mathrm{Ld}_{\mathrm{f}}}{8} \mathrm{D}\left(\frac{\mathrm{m}^{2}}{\mathrm{~L}^{2}}+\frac{\mathrm{n}^{2}}{\mathrm{~d}_{\mathrm{f}}^{2}}\right)^{2} \mathrm{~A}_{\mathrm{f}}{ }^{2}
$$

For the web the strain energy is given by: 


$$
\mathrm{U}_{\mathrm{w}}=\frac{1}{2} \cdot \mathrm{D} \pi^{4}\left[\left(\frac{\mathrm{m}^{2}}{\mathrm{~L}^{2}}+\frac{\mathrm{n}^{2}}{\mathrm{~d}_{\mathrm{w}}{ }^{2}}\right)^{2}\right] \int_{0}^{\mathrm{L}} \int_{0}^{\mathrm{d}_{\mathrm{w}}} \mathrm{w}_{\mathrm{ww}}{ }^{2} \mathrm{dxdz}
$$

Differentiating Eq. (16), $\mathrm{U}_{\mathrm{w}}$ can be found as:

$$
\mathrm{U}_{\mathrm{w}}=\frac{\mathrm{L}}{\mathrm{g}} \cdot \mathrm{D} \pi^{4}\left[\left(\frac{\mathrm{m}^{2}}{\mathrm{~L}^{2}}+\frac{\mathrm{n}^{2}}{\mathrm{dw}_{\mathrm{av}}{ }^{2}}\right)^{2}\right] \mathrm{dw_{ \textrm {av } }} \cdot \mathrm{A}_{\mathrm{w}}{ }^{2}
$$

The external work due to uniform axial force for the flange given by:

$$
\begin{gathered}
\mathrm{T}_{\mathrm{f}}=\frac{\left(\sigma_{\mathrm{cr}}\right)_{\mathrm{f}} \mathrm{t}}{2} \int_{0}^{1} \int_{0}^{\mathrm{d}_{\mathrm{f}}}\left(\frac{\partial \mathrm{w}}{\partial \mathrm{x}}\right)^{2} \mathrm{dxdy} \\
\mathrm{T}_{\mathrm{f}}=\frac{\left(\sigma_{\mathrm{cr}}\right)_{\mathrm{f}} \mathrm{t} \cdot \mathrm{m}^{2} \cdot \mathrm{m}^{2} \cdot \mathrm{d}_{\mathrm{f}}}{8 . \mathrm{L}} \mathrm{A}_{\mathrm{f}}{ }^{2}
\end{gathered}
$$

The external work due to uniform axial force for the web given by:

$$
\mathrm{T}_{\mathrm{w}}=\frac{\left(\sigma_{\mathrm{er}}\right)_{\mathrm{w}} \cdot \mathrm{t} \cdot \mathrm{m}^{2} \mathrm{~m}^{2}}{8 \mathrm{~L}} \mathrm{dw} \mathrm{wv}_{\mathrm{av}} \cdot \mathrm{A}_{\mathrm{w}}^{2}
$$

Equating the equations (20) and (17), we get the critical theoretical buckling stress of trapezoidal simply supported plate under compression as:

$$
\sigma_{\mathrm{cr}}=\mathrm{K}_{\mathrm{tr}} \frac{\pi^{2} \mathrm{D}}{\mathrm{t}_{\mathrm{d} w \mathrm{z}}{ }^{2}}
$$

where $\left(\mathrm{K}^{\mathrm{tr}}\right)$ is the buckling coefficient of the trapezoidal simply supported plate and can be obtained as:

in which: $\mu=\frac{2 \mathrm{R}}{1+\mathrm{R}}$

$$
\mathrm{K}_{\mathrm{tr}}=\left(\frac{\mathrm{m} \cdot \mathrm{dw} \mathrm{w}_{\mathrm{z}}}{\mathrm{L} \cdot \mu}+\frac{\mathrm{L} \cdot \mu}{\mathrm{m}_{\mathrm{j}} \mathrm{dw} \mathrm{w}_{\mathrm{z}}}\right)^{2}(\mu)^{3}
$$

When the tapering ratio $\mathrm{R}=1.0$, Eq.(21) reduces to Eq.(3) which gives the buckling coefficient for the rectangular plate .

The energy balance for the whole section is given by:

$$
\mathrm{T}_{\mathrm{w}}+\mathrm{T}_{\mathrm{f}}=\mathrm{U}_{\mathrm{w}}+\mathrm{U}_{\mathrm{f}}
$$

$\frac{\mathrm{t} \pi^{2} \cdot}{8 \cdot \mathrm{L}} \cdot \mathrm{m}^{2}\left(\mathrm{dw} \mathrm{av}^{*}\left(\sigma_{\mathrm{cr}}\right)_{\mathrm{w}^{*}} \cdot \mathrm{A}_{\mathrm{w}}{ }^{2}+\mathrm{d}_{\mathrm{f}} \cdot\left(\sigma_{\mathrm{cr}}\right)_{\mathrm{f}} \cdot \mathrm{A}_{\mathrm{f}}{ }^{2}\right)=\frac{\pi^{4} \mathrm{~L}}{8} \mathrm{D}\left\{\mathrm{dw}_{\mathrm{av}} \cdot\left(\frac{\mathrm{m}^{2}}{\mathrm{~L}^{2}}+\frac{\mathrm{n}^{2}}{\mathrm{dw}_{\mathrm{av}}{ }^{2}}\right)^{2} \mathrm{~A}_{\mathrm{w}}{ }^{2}+\right.$ $\left.\mathrm{d}_{\mathrm{f}} \cdot\left(\frac{\mathrm{m}^{2}}{\mathrm{~L}^{2}}+\frac{\mathrm{n}^{2}}{\mathrm{~d}_{\mathrm{w}}^{2}}\right)^{2} \mathrm{~A}_{\mathrm{f}}^{2}\right\}$

At each corner the tangents to the deflected plates must be perpendicular to each other. This gives:

$$
\left(\frac{\partial \mathrm{w}_{\mathrm{f}}}{\partial \mathrm{y}}\right)_{\mathrm{y}=0}=\left(\frac{\partial \mathrm{w}_{\mathrm{w}}}{\partial z}\right)_{\mathrm{z}=0}
$$

thus

$$
\begin{gathered}
A_{f} \frac{n \pi}{d_{f}} \sin \frac{m \pi x}{L}=A_{w} \frac{n \pi}{d_{w}} \sin \frac{m \pi x}{L} \Rightarrow A_{f}=A_{w} \frac{d_{f}}{d_{W}}=A_{w}\left(\frac{2 R}{R+1}\right)\left(\frac{1}{\varphi}\right) \\
\left(\sigma_{c r}\right)_{f} \text { t. } d_{f}=\left(\sigma_{c r}\right)_{w^{*}} \text { t. } d_{w} \Rightarrow\left(\sigma_{c r}\right)_{f}=\left(\sigma_{c r}\right)_{w^{*}} \frac{d_{w}}{d_{f}}=\left(\sigma_{c r}\right)_{w^{*}}\left(\frac{R+1}{2 R}\right) \cdot \varphi
\end{gathered}
$$

Substituting the values of $A_{f}$, and $\left(\sigma_{\mathrm{cr}}\right)_{\mathrm{f}}$, in Eq.(24), leads to

$$
\begin{aligned}
& \left(\sigma_{\mathrm{cr}}\right)_{\mathrm{w}} \cdot \frac{\mathrm{tm} \mathrm{m}^{2}}{\mathrm{8} \mathrm{L}} \cdot \mathrm{m}^{2} \cdot \mathrm{dw}_{\mathrm{av}} \cdot \mathrm{A}_{\mathrm{ww}}{ }^{2}\left[1+\left(\frac{2 \mathrm{R}}{\mathrm{R}+1}\right)^{2}\left(\frac{1}{\varphi}\right)^{2}\right]=\frac{\pi^{4} \mathrm{~L}}{8} \mathrm{D} \cdot \mathrm{dw}_{\mathrm{av}}\left\{\left(\frac{\mathrm{m}^{2}}{\mathrm{~L}^{2}}+\frac{\mathrm{n}^{2}}{\mathrm{dw}_{\mathrm{av}}{ }^{2}}\right)^{2}+\right. \\
& \left.\left(\frac{1}{\varphi}\right)^{3}\left(\frac{2 \mathrm{R}}{\mathrm{R}+1}\right)^{3} \cdot\left[\frac{\mathrm{m}^{2}}{\mathrm{~L}^{2}}+\frac{\mathrm{n}^{2}}{\mathrm{dw}_{\mathrm{av}}{ }^{2}}\left(\frac{1+\mathrm{R}}{2 \mathrm{R}}\right)^{2}(\varphi)^{2}\right]^{2}\right\} \mathrm{A}^{2}{ }^{2} 5
\end{aligned}
$$


The critical theoretical buckling stress is:

$$
\left(\sigma_{\mathrm{cr}}\right)_{\mathrm{w}}=\mathrm{K}_{\mathrm{H}^{*}} \frac{\pi^{2} \cdot \mathrm{E}}{12 \cdot\left(1-\mathrm{v}^{2}\right)}\left(\frac{\mathrm{t}}{\mathrm{dw}_{\mathrm{z}}}\right)^{2}
$$

where $\left(\mathrm{K}_{\mathrm{H}}\right)$ is the buckling coefficient of the rectangular hollow section tapered column and can be obtained as:

$$
\mathrm{K}_{\mathrm{H}}=\left(\frac{\varphi^{2}}{\varphi^{2}+\mu^{2}}\right)\left\{\left(\frac{\mathrm{m}}{\phi}+\frac{\phi}{\mathrm{m}} \cdot \mu^{2}\right)^{2}+\varphi \cdot \mu\left(\frac{\mathrm{m}}{\phi}\left(\frac{1}{\varphi}\right)^{2}+\frac{\phi}{\mathrm{m}}\right)^{2}\right\}\left(\frac{1-\ln \varphi^{\mathrm{s}}}{2 \cdot \varphi}\right)
$$

This equation takes into consideration the web-flange interaction and effect of tapering ratio of web on the section capacity. When the tapering ratio $\mathrm{R}=1.0$, Eq.(29) reduces to:

$$
\mathrm{K}_{\mathrm{H}}=\left\{\left(\frac{\mathrm{m}}{\phi}+\frac{\phi}{\mathrm{m}}\right)^{2}+\varphi\left(\frac{\mathrm{m}}{\phi}\left(\frac{1}{\varphi}\right)^{2}+\frac{\phi}{\mathrm{m}}\right)^{2}\right\}\left(\frac{1-\ln \varphi^{\mathrm{s}}}{2 \cdot \varphi}\right)
$$

This equation gives the buckling coefficient for prismatic rectangular hollow section columns and takes into consideration the web-flange interaction.

Substituting the values of " $\mathrm{K}_{\mathrm{H}}{ }^{\mathrm{w}}$ in Eq.(4), can determine the critical theoretical buckling load for rectangular hollow section tapered columns. A MATLAB program is developed to determine the buckling load of thin-walled box-sections subjected to uniform compressive load.

Figure 2 shows the buckling coefficient of a simply supported plate for different aspect ratios $\left(\Phi=\mathrm{L} / \mathrm{d}_{\mathrm{w} 2}\right)$ and for different values of tapering ratio $\left(\mathrm{R}=\mathrm{d}_{\mathrm{w} 2} / \mathrm{d}_{\mathrm{w} 11}\right)$. Figure 3 shows the buckling coefficient of hollow section columns for different values of web depth-to- flange width ratio $" \mathrm{~d}_{\mathrm{w} 2} / \mathrm{d}_{\mathrm{f}}$ ". and for tapering ratio $(\mathrm{R}=1.0)$.

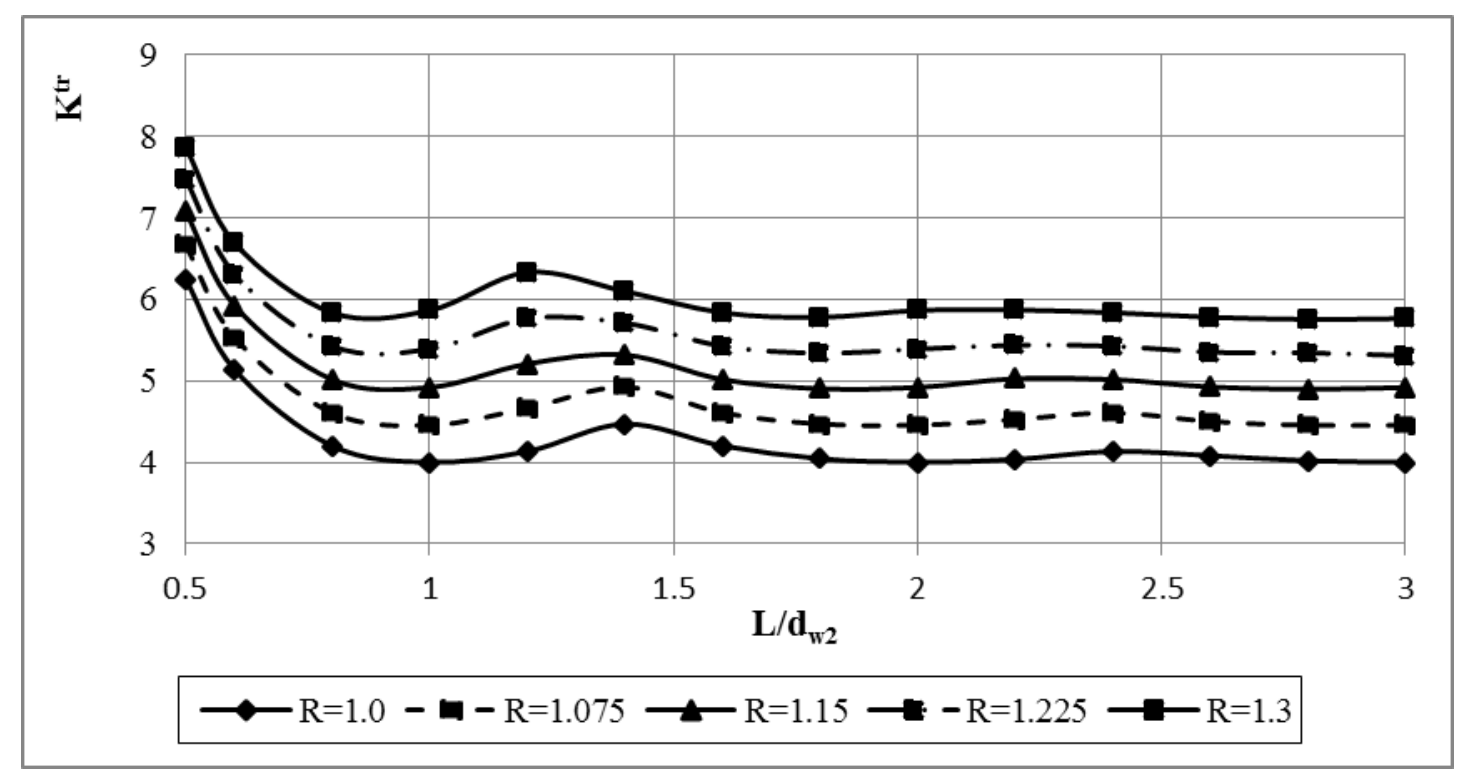

Fig. 2 Buckling coefficient of the plate for different tapering ratios $(R)$ 


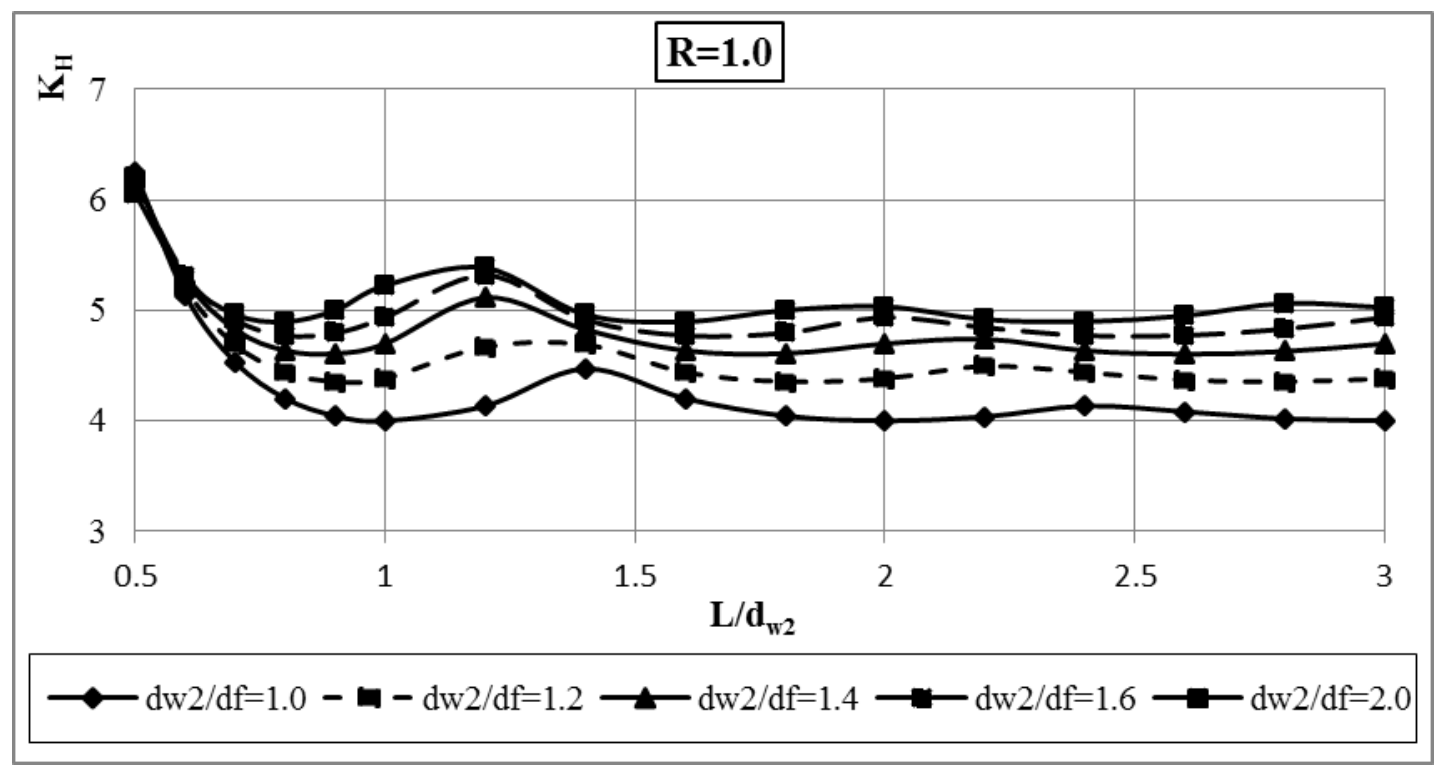

Fig. 3 Buckling coefficient of hollow section columns at $(R=1.0)$

\section{Finite Element Model}

The commercial multipurpose finite element software program ANSYS (2012) was employed in this research. The general-purpose Eight node quadrilateral thin shell element "Shell 93" with membrane and bending capabilities which is suitable for three dimensional structural analysis and suitable to be used for the column cross section. The element has isotropic material properties and constant thickness. Generally, the flanges were divided into 8 elements for $d_{w 2} / d_{f}=1.5,6$ elements for $d_{w 2} / d_{f}=2.0$ and 2.5 , and 4 elements for $\mathrm{d}_{\mathrm{w} 2} / \mathrm{d}_{\mathrm{f}}=3.0$. while webs divided into 12 elements for $\mathrm{d}_{\mathrm{w} 2} / \mathrm{d}_{\mathrm{w} 1}=1.0,10$ elements ford $_{\mathrm{ww} 2} / \mathrm{d}_{\mathrm{w} 1}=1.2,8$ elements for $\mathrm{d}_{\mathrm{w} 2} / \mathrm{d}_{\mathrm{w} 1}=1.4$, and 6 elements for $\mathrm{d}_{\mathrm{w} 2} / \mathrm{d}_{\mathrm{w} 1}=2.0$. The column is divided into 60 elements in the longitudinal direction. End plate of thickness 30 $\mathrm{mm}$ was at each end of the model to avoid stress concentration at the locations of the column loading and supporting points. To represent the two supports, the nodes of one of the two ends-plates is restrained from translation in the three main directions $\left(U_{x}, U_{y}\right.$ and $\left.U_{z}\right)$ in addition to rotation about longitudinal axis $\left(\mathrm{r}_{\mathrm{y}}\right)$; while the nodes of the second end plate is restrained from translation in the two main directions $\left(\mathrm{U}_{\mathrm{x}}\right.$ and $\mathrm{U}_{\mathrm{z}}$ ) and rotation about longitudinal axis $\left(\mathrm{r}_{\mathrm{y}}\right)$, translation is allowed in the direction of the longitudinal axis column to allow the column to deform longitudinally due to normal force $(\mathrm{P})$. The material of the plates was assumed to be homogeneous, isotropic and elastic. Young's modulus E $=210 \mathrm{GPa}$ and Poisson's ratio $v=0.3$ were selected. The linear buckling analysis (or eigenvalue analysis) is performed in two steps. The first step is an elastic linear analysis which is performed to determine the internal reactions (initial stresses) in the structure due to externally applied loads. The second step is to determine eigenvalue based on the geometric stiffness matrix obtained from the linear analysis.

The deformed shapes of trapezoidal plates and rectangular hollow section tapered columns resulting from the finite element model are shown in Figs 4 and 5. 


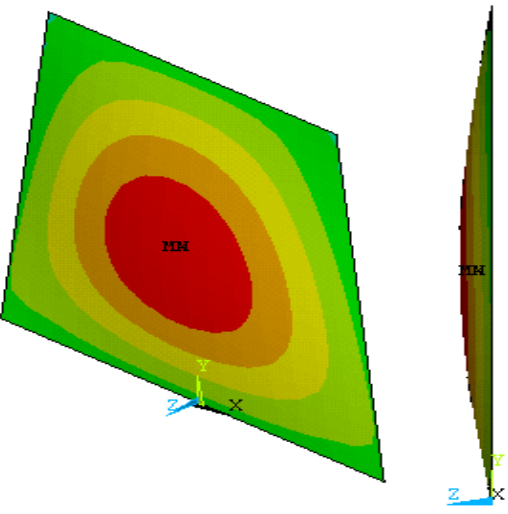

(a)- $\Phi=1.0 \& R=1.3$
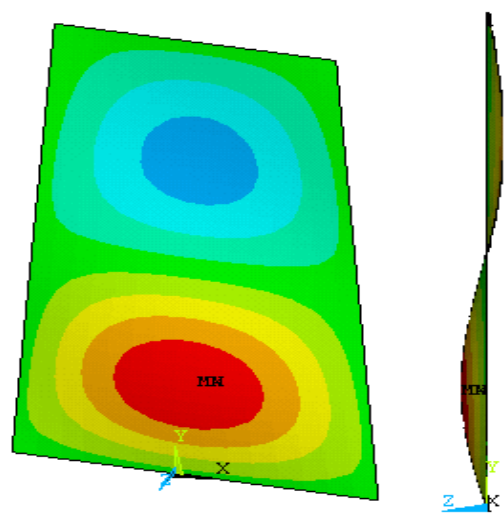

(b)- $\Phi=1.8 \& R=1.3$

Fig. 4 Deformed shape of trapezoidal plate
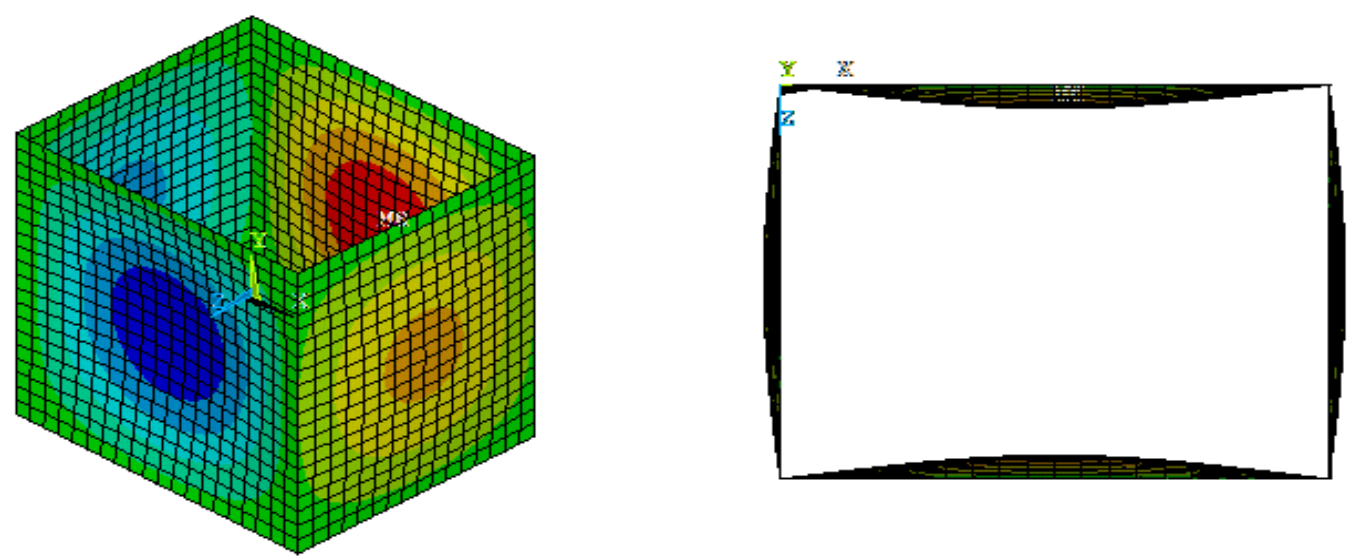

(a)- Square hollow section column $\left(\Phi=1.0 \& R=1.0 \& \mathrm{~d}_{\mathrm{w} 2} / \mathrm{d}_{\mathrm{f}}=1.2\right)$
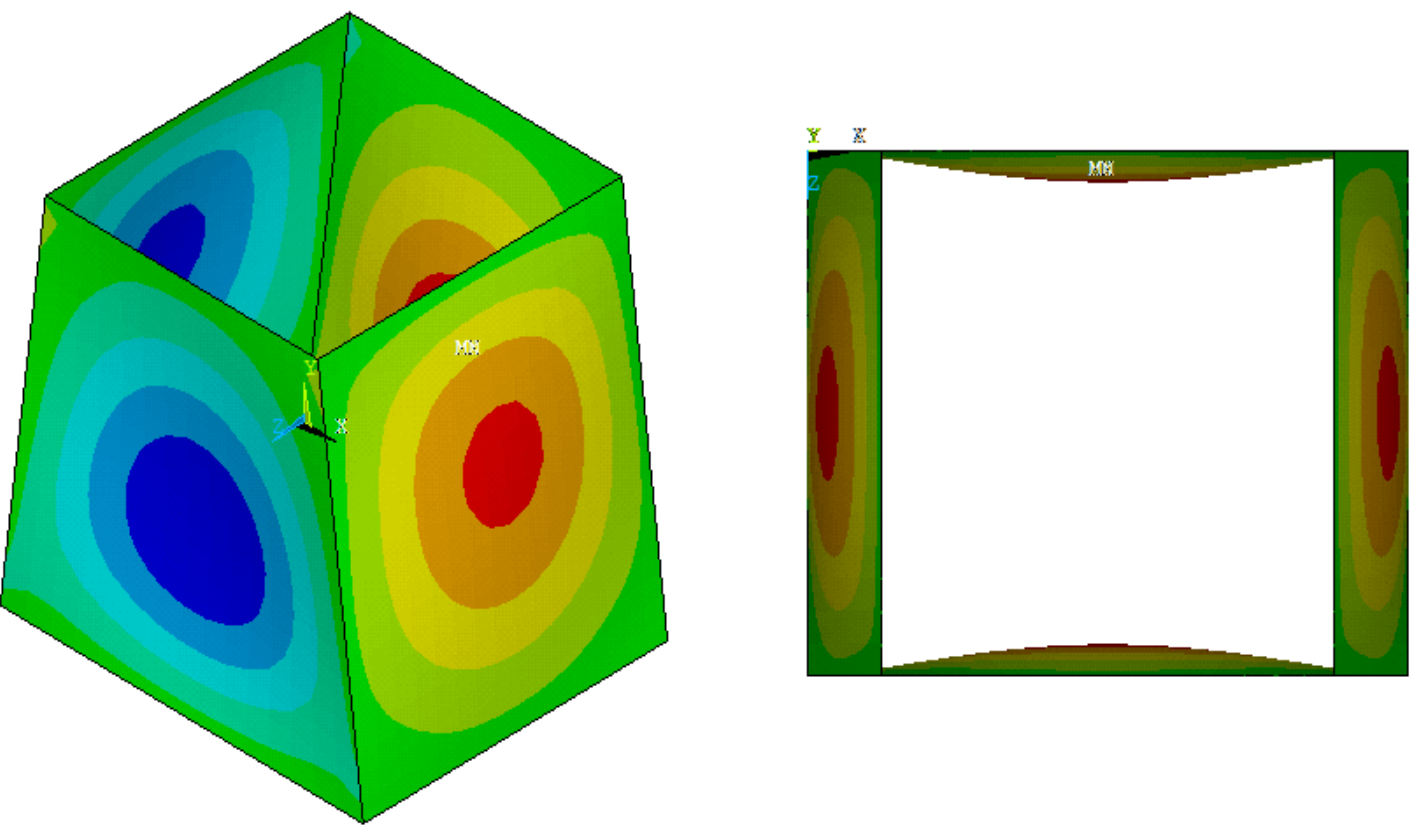

(b)- Rectangular hollow section tapered column $\left(\Phi=1.0 \& R=1.3 \& \mathrm{~d}_{\mathrm{w} 2} / \mathrm{d}_{\mathrm{f}}=1.2\right)$

Fig. 5 Deformed shape of hollow section columns 


\section{Results and Discussion}

The ratio of the critical load to average area yield load $\left(\mathrm{P}_{\mathrm{cr}} / \mathrm{P}_{\mathrm{y}, \mathrm{av}}\right)$ is plotted versus the ratio of ${ }^{"} \mathrm{~d}_{\mathrm{w} 2} / \mathrm{t}^{\mathrm{I}}$ for different chosen practical ranges of tapering ratio $\left(\mathrm{R}=\mathrm{d}_{\mathrm{w} 2} / \mathrm{d}_{\mathrm{w} 11}\right)$, and different values of web depth-to- flange width ratio $" \mathrm{~d}_{\mathrm{w} 2} / \mathrm{d}_{\mathrm{f}}$ ". It is clear from these curves that the relationship between the critical load to average area yield load $\left(\mathrm{P}_{\mathrm{cr}} / \mathrm{P}_{\mathrm{y}, \mathrm{av}}\right)$ and bottom web depth -to- thickness ratio " $\mathrm{d}_{\mathrm{w} 2} / \mathrm{t}^{\mathrm{t}}$ is an inversely proportional relationship as $\left(\mathrm{P}_{\mathrm{cr}} / \mathrm{P}_{\text {yav }}\right)$ increases with the decrease of ${ }^{\mathrm{m}} \mathrm{d}_{\mathrm{w} 2} / \mathrm{t}^{\mathrm{t}}$. Also, it can be noticed that the ratio of $\left(\mathrm{P}_{\mathrm{cr}} / \mathrm{P}_{\mathrm{yav}}\right)$ increases with the increase of tapering ratio $(\mathrm{R})$. It is noticed from the curves that the relation is almost linear for the range of $\mathrm{d}_{\mathrm{w} 2} / \mathrm{t}=150$ to $\mathrm{d}_{\mathrm{w} 2} / \mathrm{t}=300$ for all ranges of $\left(\mathrm{d}_{\mathrm{w} 2} / \mathrm{d}_{\mathrm{f}}\right)$ and the tapering ratio $\mathrm{R}$.

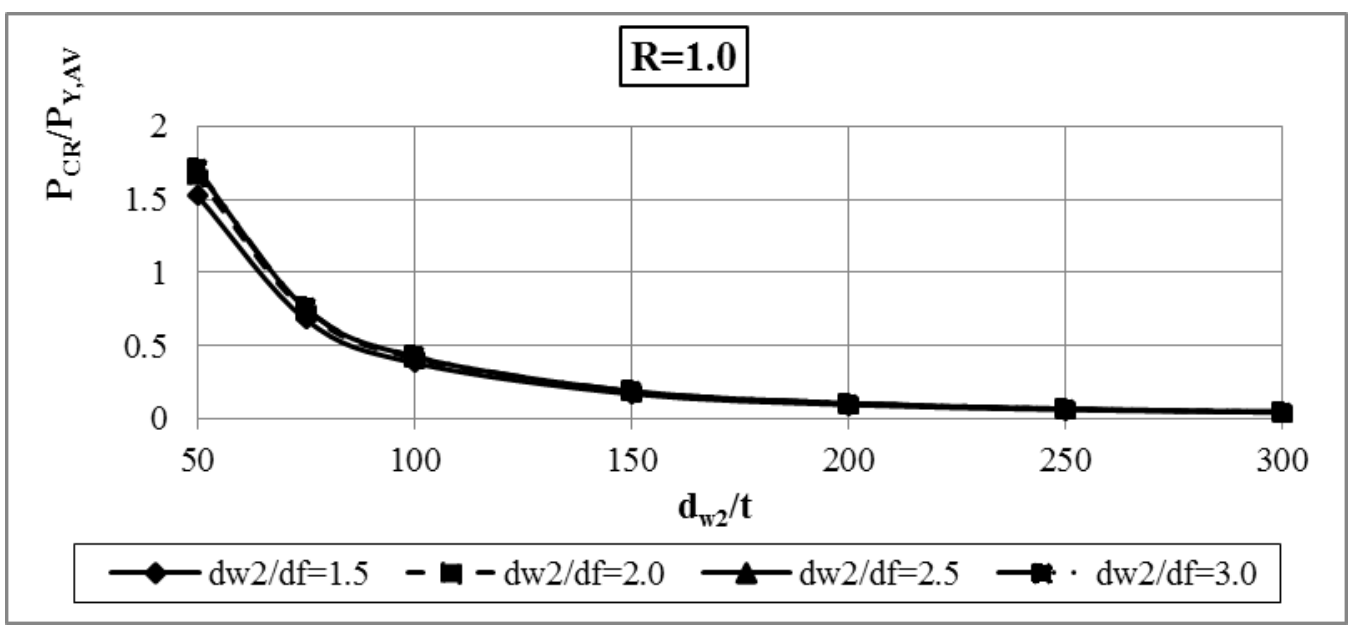

Fig. 6 Effect of the ratios $\left(d_{w 2} / t\right)$ on strength of HSC for different values of " $d_{w 2} / d_{f}{ }^{"}$ at $(R=1)$

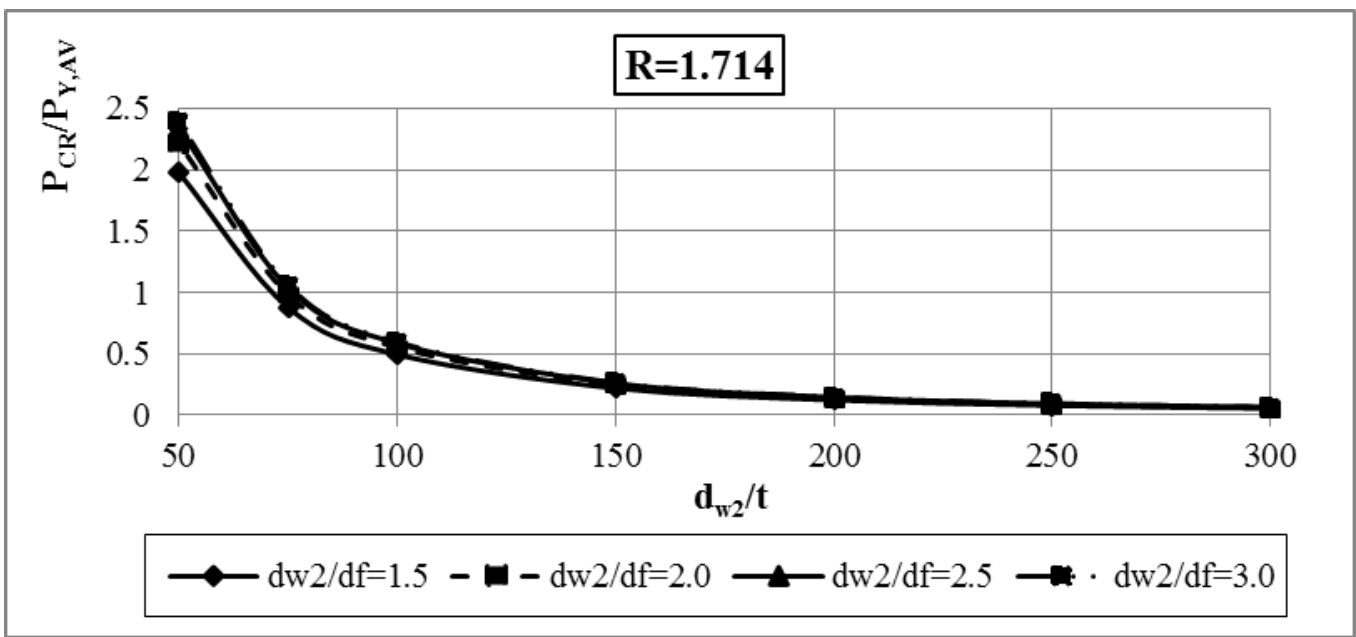

Fig. 7 Effect of the ratios $\left(d_{w 2} / t\right)$ on strength of HSC for different values of ${ }^{"} d_{w 2} / d_{f}{ }^{"}$ at $(R=1.714)$ 


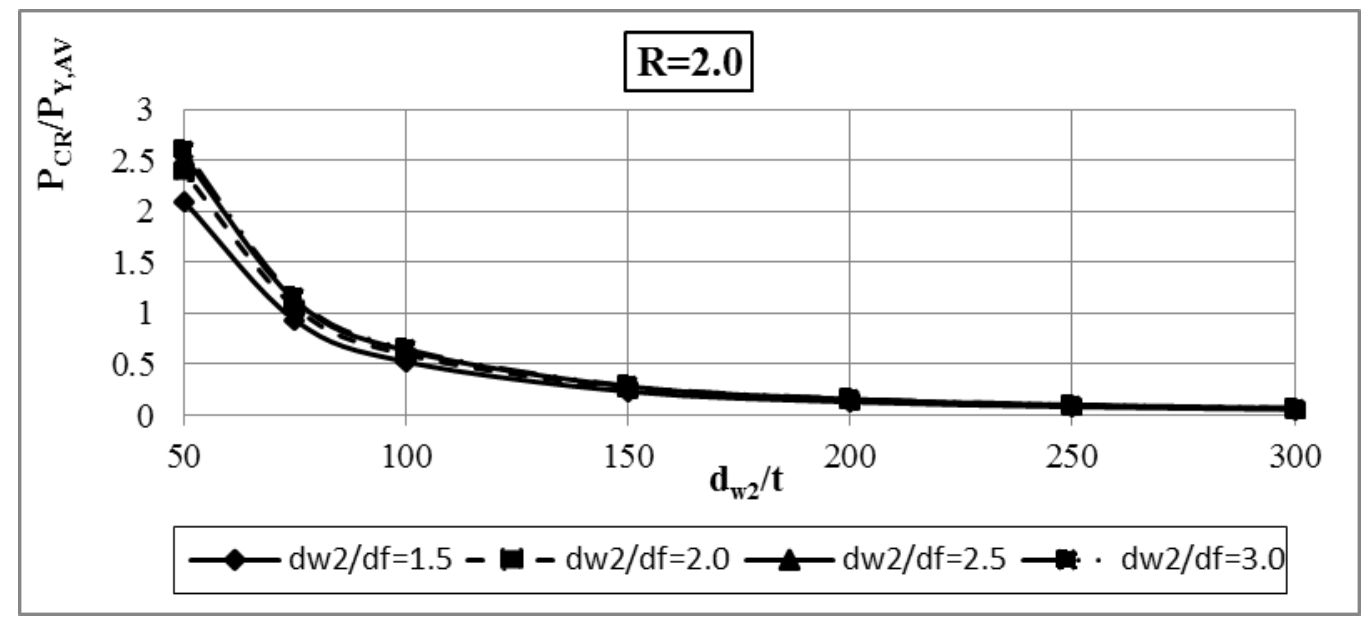

Fig. 8 Effect of the ratios $\left(d_{w 2} / t\right)$ on strength of HSC for different values of ${ }^{"} d_{w 2} / d_{f}{ }^{w}$ at $(R=2)$

\section{Comparison between Proposed Model Equation and F.E.M}

The results obtained from the previously mentioned theoretical analysis (proposed model equation) are compared with the finite element analyses. This comparison is illustrated in a set of curves for all the studied plates and columns.

Figure 9 represents the relationship between the ratio of buckling coefficient of plates $(\mathrm{K})$ versus aspect ratio " $\phi=\mathrm{d}_{\mathrm{w}_{\mathrm{z}}} / \mathrm{t}^{\mathrm{w}}$ for the proposed model equation and finite element results for tapering ratio $(\mathrm{R})=1.0$ and 1.3 .

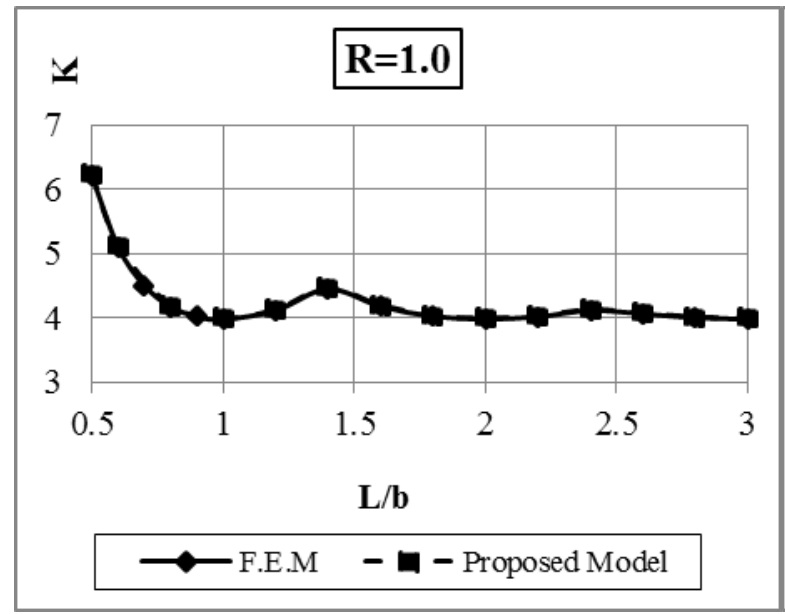

(a)

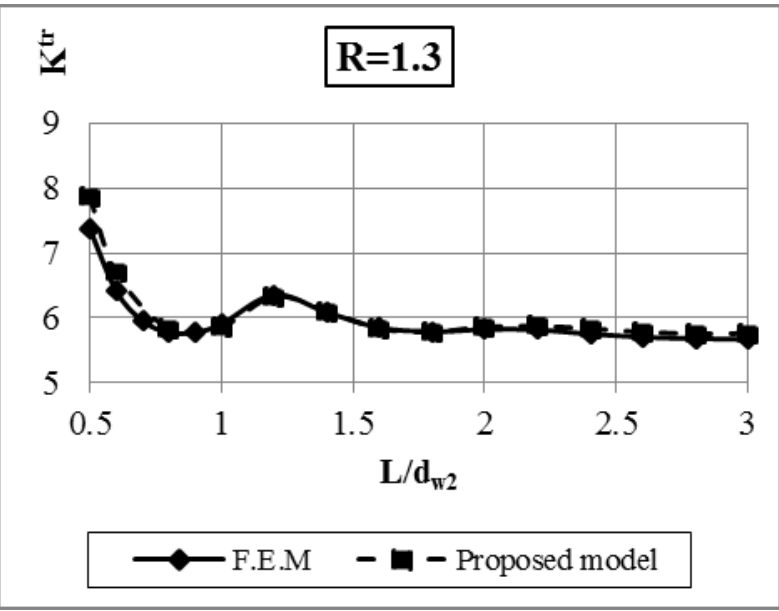

(b)

Fig. 9 Comparison between F.E.M. and proposed model(plate) results for $(a-R=1.0 \& b-R=1.3)$

Figures 10 to 18 represent the relationship between the ratio of buckling load to average area yield load $\left(\mathrm{P}_{\mathrm{CR}} / \mathrm{P}_{\text {y,av }}\right)$ versus bottom web depth -to- thickness ratio ${ }^{\text {"d }} \mathrm{d}_{\mathrm{w} 2} / \mathrm{t}^{\mathrm{w}}$ for the proposed model equations and finite element results for tapering ratio $(\mathrm{R})=1.0,1.2$ and 2.0 at $\mathrm{d}_{\mathrm{w} 2} / \mathrm{d}_{\mathrm{f}}$ $=1.5,2.0$ and 3.0. All figures show that the proposed model equations and the finite element model give the same results for all the specimens. 


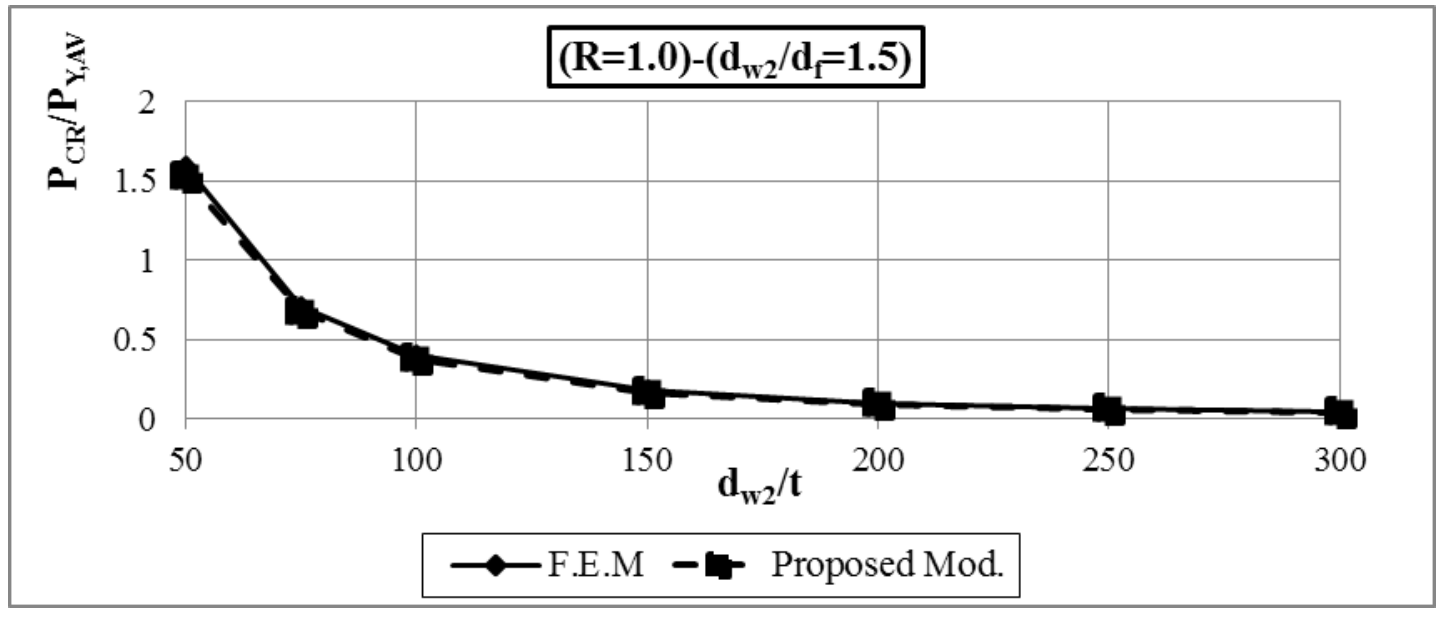

Fig. 10 Comparison between F.E.M. and proposed model(column) results for $\left(R=1.0\right.$ andd $\left._{w 2} / d_{f}=1.5\right)$

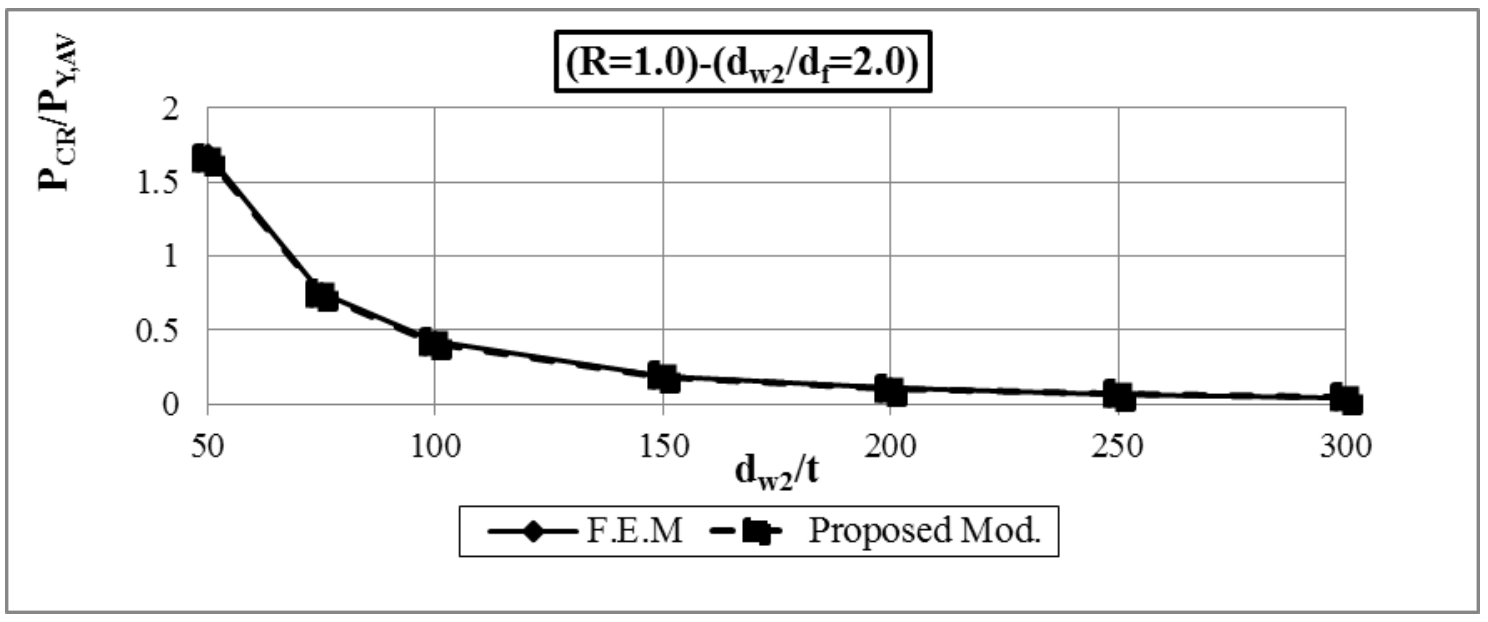

Fig. 11 Comparison between F.E.M. and proposed model(column) results for $\left(R=1.0\right.$ and $\left.d_{w 2} / d_{f}=2.0\right)$

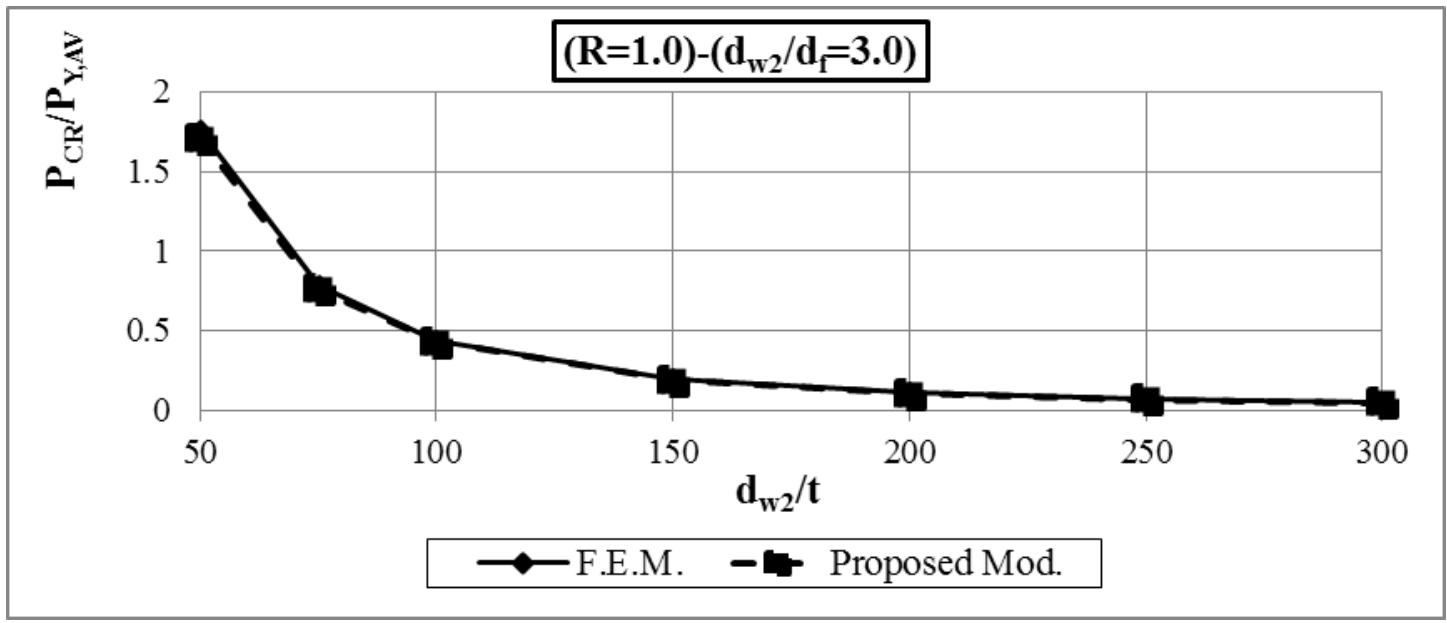

Fig. 12 Comparison between F.E.M. and proposed model(column) results for

$$
\left(R=1.0 \text { andd }_{w 2} / d_{f}=3.0\right)
$$




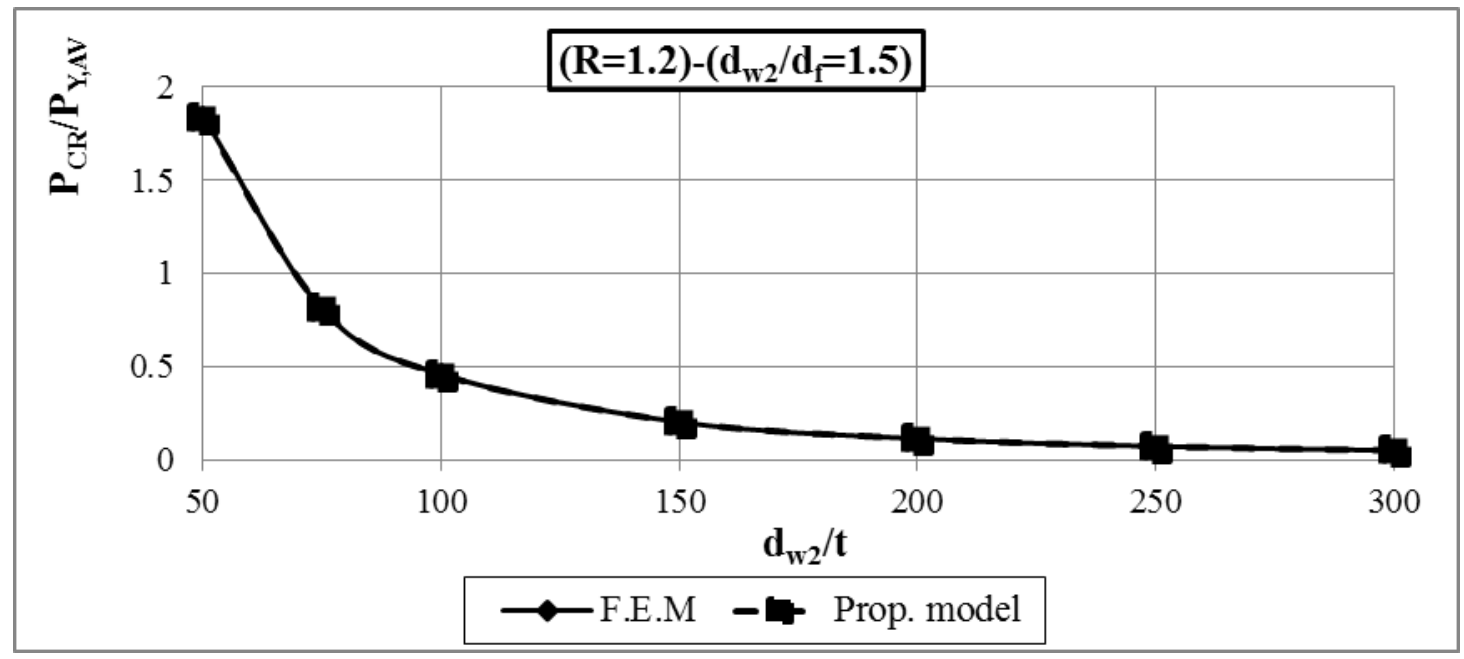

Fig. 13 Comparison between F.E.M. and proposed model(column) results for $\left(R=1.2\right.$ and d $\left._{\mathrm{w} 2} / \mathrm{d}_{\mathrm{f}}=1.5\right)$

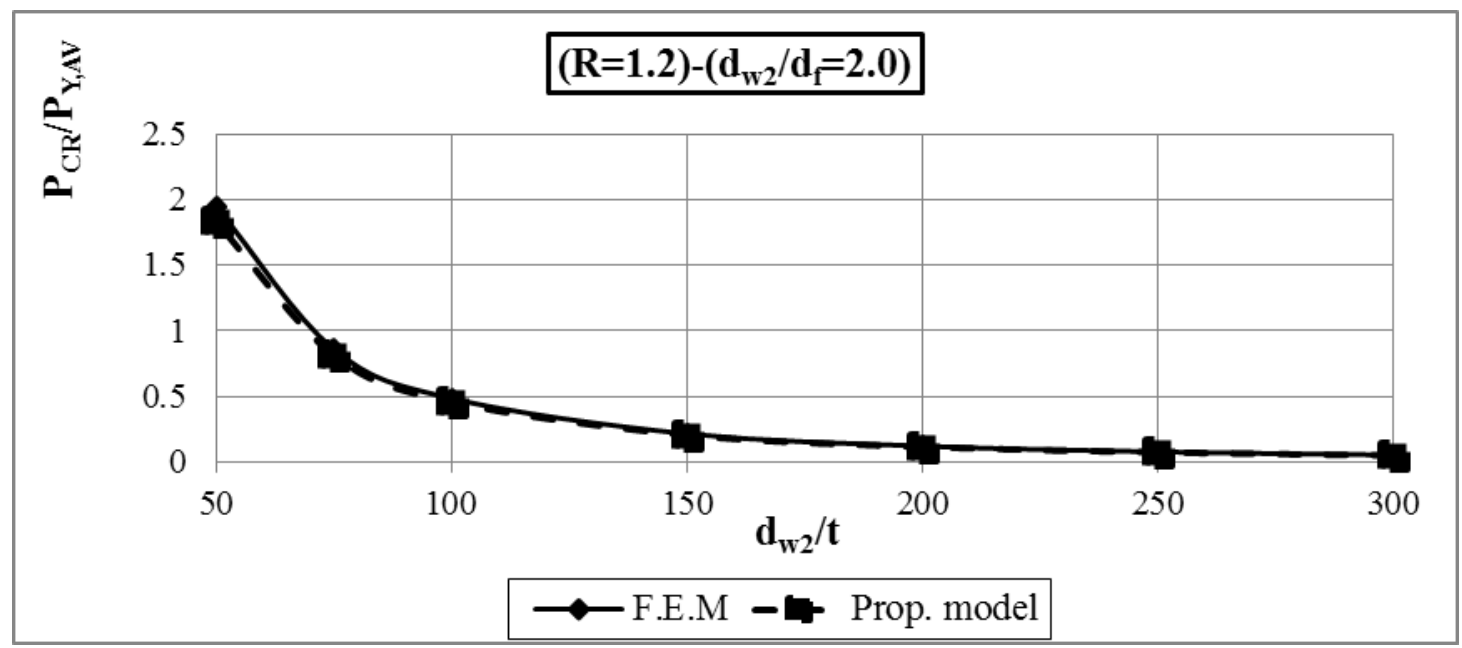

Fig. 14 Comparison between F.E.M. and proposed model results for $\left(R=1.2\right.$ and d $\left._{w 2} / d_{f}=2.0\right)$

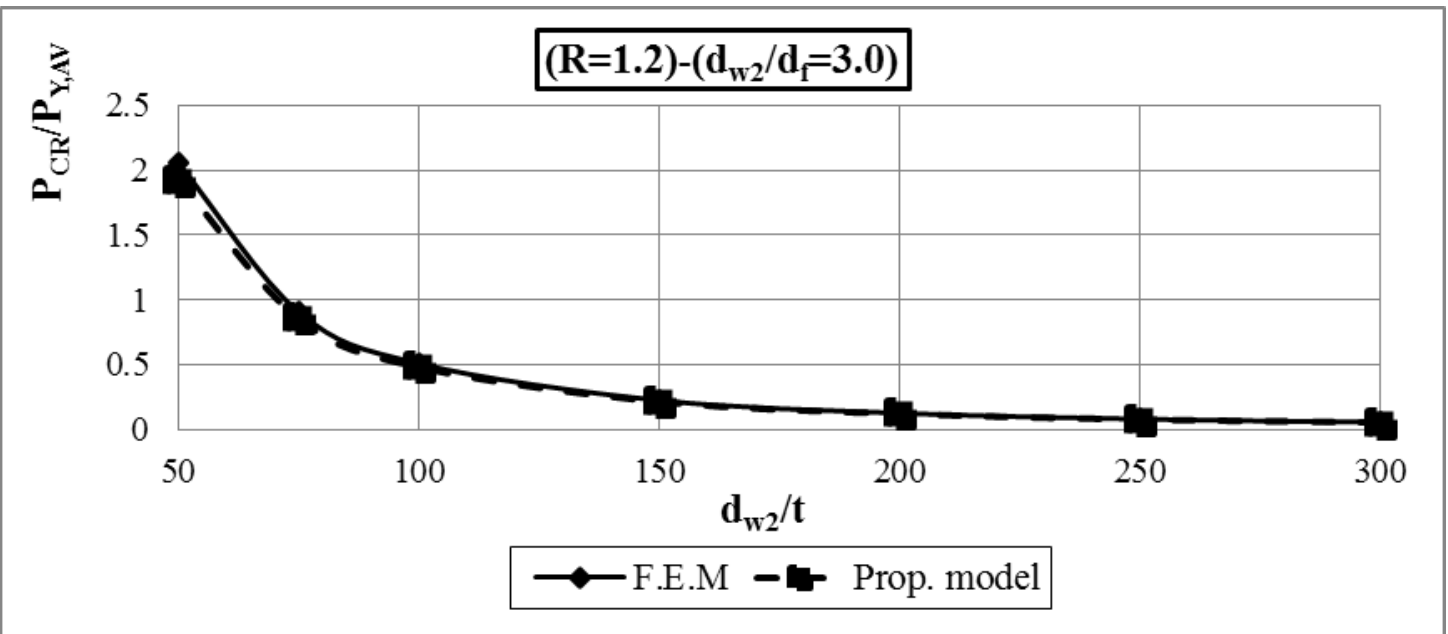

Fig. 15 Comparison between F.E.M. and proposed model results for $\left(R=1.2\right.$ andd $\left._{w 2} / d_{f}=3.0\right)$ 


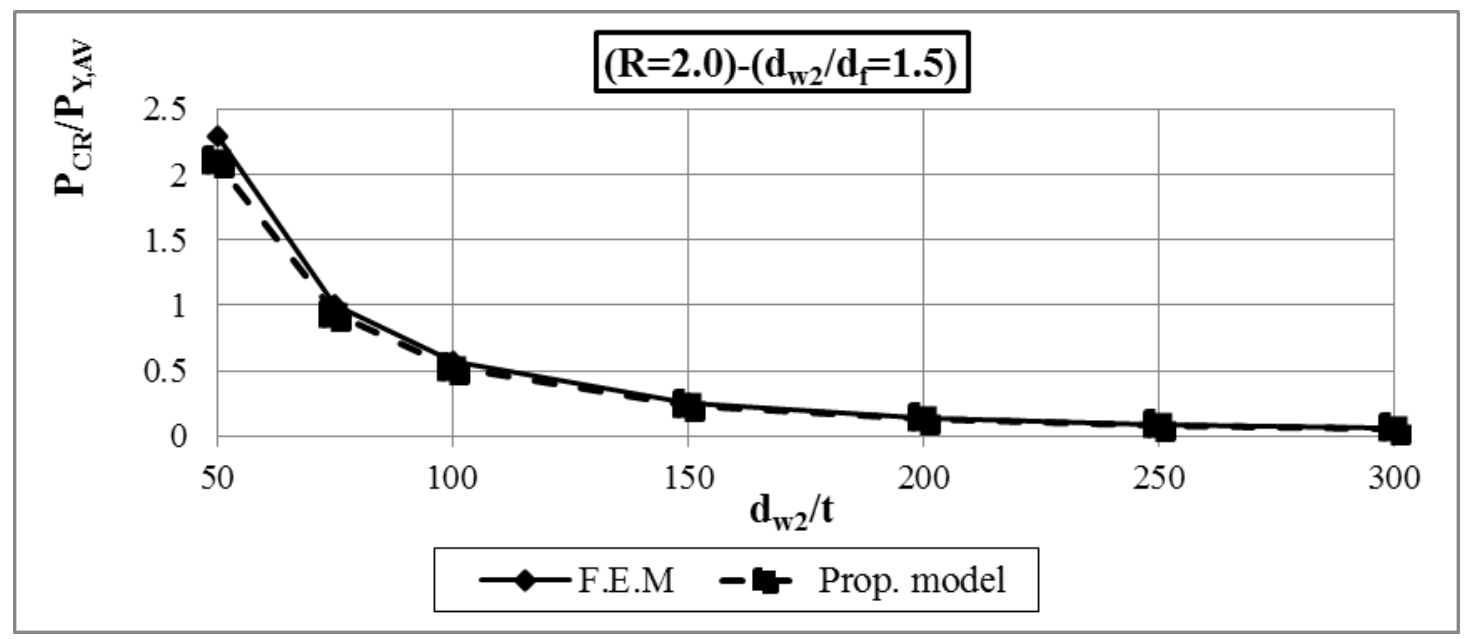

Fig. 16 Comparison between F.E.M. and proposed model results for $\left(R=2.0\right.$ and d $\left._{w 2} / d_{f}=1.5\right)$

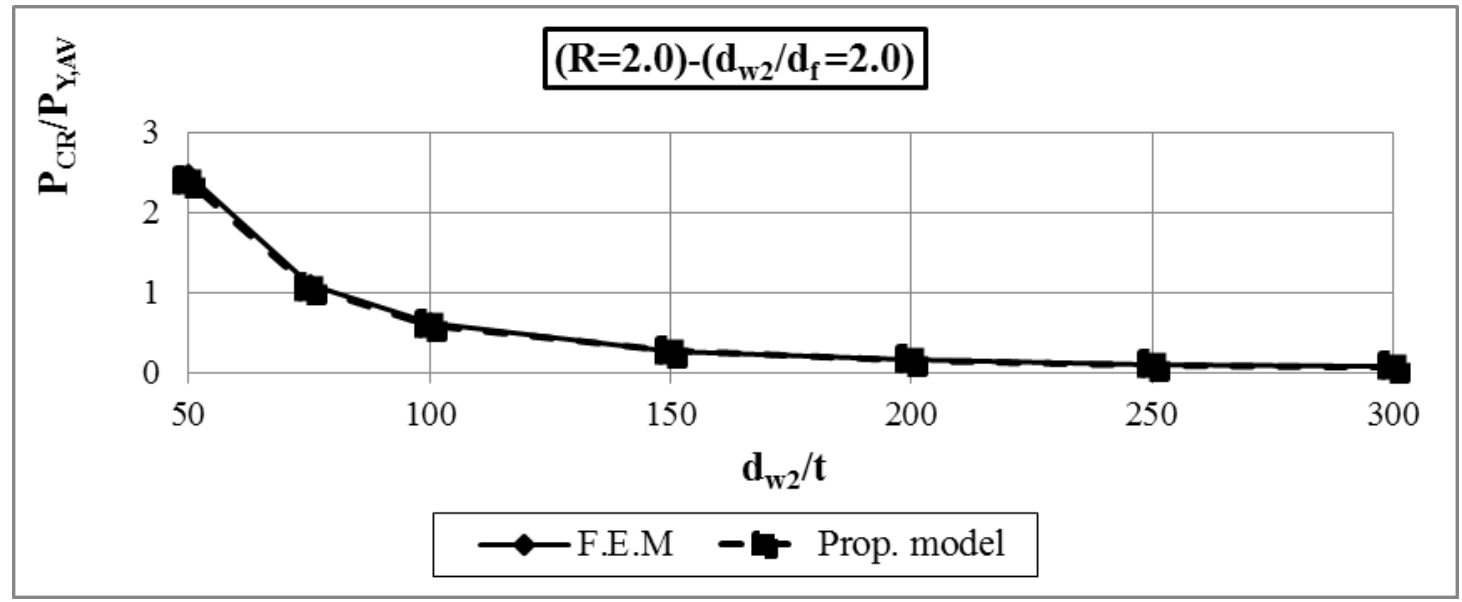

Fig. 17 Comparison between F.E.M. and proposed model results for $\left(R=2.0\right.$ andd $\left._{w 2} / d_{f}=2.0\right)$

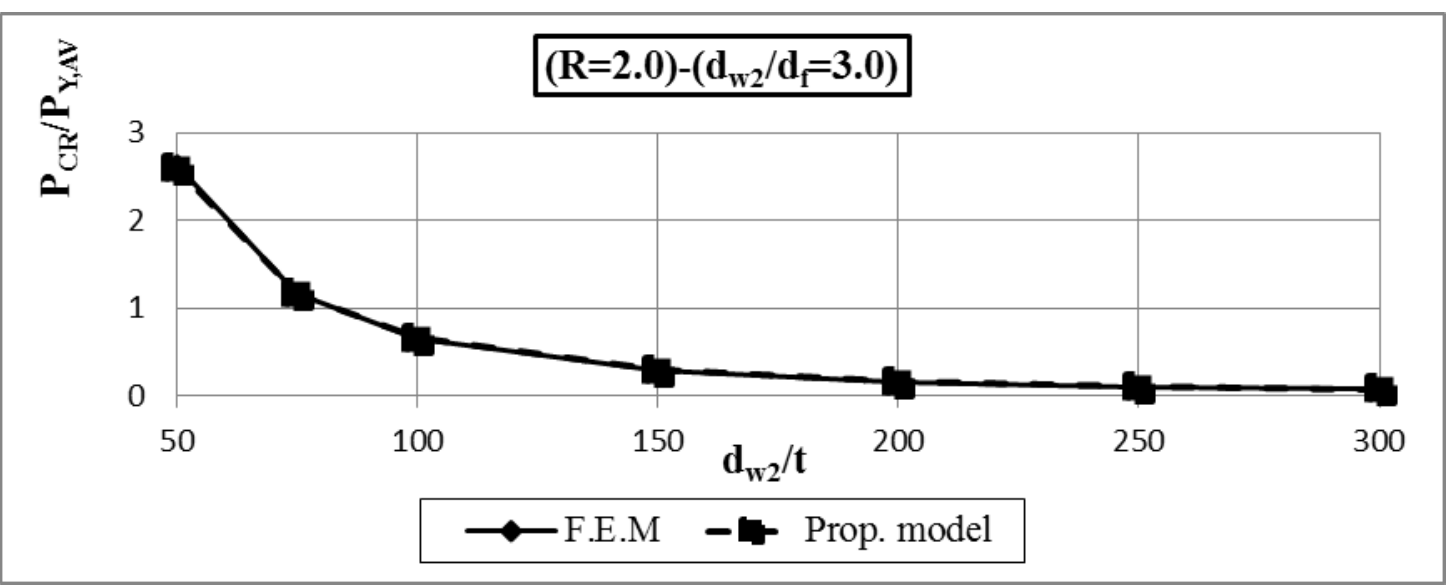

Fig. 18 Comparison between F.E.M. and proposed model results for $\left(R=2.0\right.$ andd $\left._{w 2} / d_{f}=3.0\right)$ 


\section{Conclusions}

The results obtained lead to the following conclusions:

- The buckling coefficient for trapezoidal plates and also for tapered columns is higher than the corresponding coefficient of rectangular plates and rectangular hollow section columns, when compared with the wide web width.

- The buckling coefficient for column with $\mathrm{R}=1.0$ and $\left(\mathrm{d}_{\mathrm{w} 2} / \mathrm{d}_{\mathrm{f}}=1.0\right)$, is equal to the buckling coefficient of a single simply supported rectangular plate.

- The relationship between the critical load to average area yield load ratio $\left(\mathrm{P}_{\mathrm{cr}} / \mathrm{P}_{\text {yav }}\right)$ and wide web depth-to-thickness ratio ${ }^{~} \mathrm{~d}_{\mathrm{w} 2} / \mathrm{t}$ is an inversely proportional relationship as $\left(\mathrm{P}_{\mathrm{cr}} / \mathrm{P}_{\text {yav }}\right)$ increases with the decrease of ${ }^{\mathrm{m}} \mathrm{d}_{\mathrm{w} 2} / \mathrm{t}$.

- The critical load to average area yield load ratio $\left(\mathrm{P}_{\mathrm{cr}} / \mathrm{P}_{\text {yav }}\right)$ increases with the increase of the wide web depth -to- flange width ratio $\left(\mathrm{d}_{\mathrm{w} 2} / \mathrm{d}_{\mathrm{f}}\right)$, as well as with the increase of the tapering ratio $(\mathrm{R})$.

- The proposed model equations and the finite element model give very similar results for all values of $\phi$ and $R$.

\section{References}

[1] D. Yang, G.J. Hancock and K.J. Rasmussen, "Compression Tests of Cold-Reduced High Strength Steel Long Columns", Centre for Advanced Structural Engineering, Research Report No 816 (2002).

[2] A. H. Salem et al., "Ultimate Strength of Cold-Formed RHS Columns", Tenth International Colloquium on Structural and Geotechnical Engineering, Ain Shams University, Cairo, Egypt ( 2003).

[3] D. Yang, "Compression Stability of High Strength Steel Section With Low StrainHardening", Thesis presented to University of Sydney, Australia, for the degree of Doctor of philosophy (2003).

[4] Demao Yang and Gregory J Hancock, "Numerical Simulations of High Strength Steel Lipped-Channel Columns", Centre for Advanced Structural Engineering, Research Report No 843 (2004).

[5] Demao Yang and Gregory J Hancock, "Numerical Simulations of High Strength Steel Box-Shaped Columns", Centre for Advanced Structural Engineering, Research Report No 842 (2004).

[6] Derrick and G.J.Hancock, "Compression Tests of High Strength Cold-Formed CrossSection Steel Columns", Centre for Advanced Structural Engineering, Research Report No R869,Univ.of Sydney (2006).

[7] T. H. Seong, "Behaviour of Cold-Formed Steel Under Axial Compression Force", A project report submitted in partial fulfillment of the requirements for the award of the degree of Master of Engineering . University Technology of Malaysia (2008).

[8] Dabaon, et al., "Numerical Modeling for Stiffened and Unstiffened Stainless Steel Hollow Tubular Columns", 13th ICSGE, Ain Shams University, Cairo, Egypt(2009).

[9] R. Masoudnia, et al., "Numerical Investigation of Behavior of RHS Columns Using FE Method", European Journal of Scientific Research ,Vol.51 No.1 (2011), pp.109-114. 